06

\title{
Влияние облучения низкоэнергетическими ионами гелия на спектральный коэффициент отражения монокристаллических молибденовых зеркал
}

\author{
(C) А.В. Рогов, ${ }^{1,2}$ Ю.В. Капустин, ${ }^{1,2}$ Ю.В. Мартыненко ${ }^{1,3}$ \\ ${ }^{1}$ Национальный исследовательский центр „Курчатовский институт“, \\ 123182 Москва, Россия \\ ${ }^{2}$ Автономная некоммерческая организация Координационный центр \\ „Управляемый термоядерный синтез - международные проекты“, \\ Москва, Россия \\ ${ }^{3}$ Национальный исследовательский ядерный университет „МИФИ“, \\ 115409 Москва, Россия \\ e-mail: alex-rogov@yandex.ru
}

Поступило в Редакцию 15 февраля 2021 г.

В окончательной редакции 16 марта 2021 г.

Принято к публикации 15 апреля 2021 г.

\begin{abstract}
Представлены результаты сравнительного исследования влияния облучения ионами гелия на оптические свойства монокристаллических молибденовых зеркал с кристаллографической ориентацией $\langle 110\rangle$ и $\langle 111\rangle$. Режим облучения соответствует условиям во встроенных системах плазменной очистки входных зеркал от загрязнений в оптических диагностиках международного термоядерного реактора ИТЭР при использовании гелия в качестве рабочего газа. В результате такого облучения происходит изменение зеркального отражения и диффузного рассеяния зеркала, которое практически не зависит от начальной структуры приповерхностного слоя зеркала и длительности процесса облучения. Авторы объясняют наблюдаемые изменения оптических характеристик зеркала формированием в приповерхностном скин-слое наноразмерных пузырьков. Рэлеевское рассеяние на них падающего излучения уменьшает интенсивность зеркального отражения и увеличивает диффузное рассеяние. Предложена модель образования и роста наноразмерных пузырьков и их влияния на оптические свойства. Полученные результаты следует учитывать при анализе экспериментальных данных в оптических диагностиках ИТЭР после удаления загрязнений с использованием гелия, при выборе рабочего газа для систем плазменной очистки зеркал, а также для формирования нанопористой структуры в тонком поверхностном слое металлов.
\end{abstract}

Ключевые слова: монокристаллический молибден, очистка зеркал, рэлеевское рассеяние, зеркальное отражение, диффузное рассеяние.

DOI: $10.21883 / J T F .2021 .09 .51216 .37-21$

\section{Введение}

Одним из основных требований при разработке систем оптической диагностики плазмы международного термоядерного реактора ИТЭР является обеспечение их работоспособности в течение как минимум 4 лет [1] без замены внутривакуумных оптических компонентов. Наибольшему негативному воздействию подвержено входное зеркало, принимающее излучение непосредственно из термоядерной плазмы. В зависимости от режима работы реактора и во время аварийных ситуаций отражающая поверхность этого зеркала может либо распыляться атомами перезарядки [2], либо загрязняться за счет переосаждения продуктов эрозии компонентов реактора, обращенных к плазме (Be, $\mathrm{Fe}, \mathrm{Cr}, \mathrm{W}$ и др.) [3], и химического взаимодействия с агрессивной средой (водяной пар, кислород и др.). С учетом возможности загрязнения в состав всех систем оптической диагностики установки ИТЭР должна входить встроенная система плазменной очистки отражающей поверхности входного зеркала на основе низкоэнергетического ионного распыления в газовом разряде $[4,5]$. В качестве конструкционного материала для изготовления входных зеркал нескольких диагностических систем предполагается использовать монокристаллический Мо [6,7].

Для проведения очистки зеркал предусмотрен специальный режим установки с повышением давления в вакуумной камере до $1-7 \mathrm{~Pa}$, а в качестве рабочих газов допустимо использовать $\mathrm{H}_{2}, \mathrm{D}_{2}, \mathrm{He}, \mathrm{Ne}$, $\mathrm{Ar}$ и их смеси. Применение этих газов (особенно $\mathrm{D}_{2}$ ) при проведении очистки зеркал обеспечивает наименьшее последующее загрязнение термоядерной плазмы тяжелыми примесями за счет газоотделения из элементов оборудования, установленного в диагностических портах, и со стенок вакуумной камеры. Однако в этом случае по сравнению с другими допустимыми к использованию газами (Ne, $\mathrm{Ar}$ ) для основных загрязнителей $(\mathrm{Be}, \mathrm{W})$ [8] коэффициент распыления имеет минимальное значение.

В настоящей работе представлены результаты исследования влияния на спектральный коэффициент отра- 
жения полированных Мо монокристаллических зеркал бомбардировки ионами Не при использовании этого газа для плазменной очистки отражающей поверхности.

\section{1. Методика эксперимента}

Облучение образцов ионами $\mathrm{He}^{+}$и $\mathrm{Ar}^{+}$проводилось в разряде с цилиндрическим сеточным полым катодом диаметром $92 \mathrm{~mm}$ и длиной $140 \mathrm{~mm}$, с размером ячейки $2.5 \times 2.5 \mathrm{~mm}$, изготовленным из нержавеющей стали. В экспериментах использовались механически полированные монокристаллические зеркала с кристаллографической ориентацией $\langle 110\rangle$ и $\langle 111\rangle$, диаметром $25 \mathrm{~mm}$ и толщиной $3 \mathrm{~mm}$. Изготовитель - НПО „Луч“, г. Подольск. Образцы зеркал закреплялись внутри полого катода на его „донышке“. В качестве анода использовался планарный магнетрон с дисковым катодом диаметром $25 \mathrm{~mm}$ в режиме инверсного включения [9]. Такая конфигурация обеспечивает увеличение разрядного тока, расширение диапазона допустимых рабочих давлений рабочего газа и уменьшение разрядного напряжения. Разрядная ячейка находилась под плавающим потенциалом относительно стенок вакуумной камеры. Схема эксперимента представлена на рис. 1.

При таком включении электродов газовый разряд локализуется внутри полого катода, а его сетчатая конструкция обеспечивает облегченный уход продуктов эрозии из зоны разряда. За счет этого обеспечивается повышенная эффективность распыления внутренней стенки полого катода, на которой размещается исследуемый образец зеркала.

В ходе экспериментов моделировался режим удаления загрязнений в системах плазменной очистки входных зеркал, разрабатываемых в России для диагностических систем ИТЭР „Спектроскопия водородных линий“ и „Активная спектроскопия“ [6,7]. Проведено сравнение устойчивости к воздействию облуче-

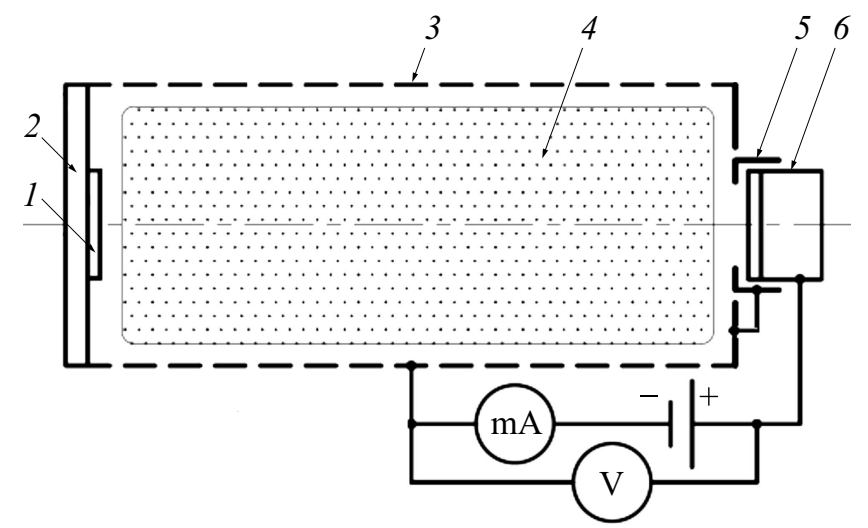

Рис. 1. Схема эксперимента по облучению зеркал ионами $\mathrm{He}^{+}$ и $\mathrm{Ar}^{+}: 1$ - зеркало, 2 - подложкодержатель, 3 - цилиндрический сеточный полый катод, 4 - область локализации плазмы, 5 - анод магнетрона, $6-$ водоохлаждаемый корпус магнетрона. ния ионами гелия молибденовых монокристаллических зеркал с разной кристаллографической ориентацией для выбора их структуры. Использовался следующий режим облучения ионами гелия: напряжение разряда $U_{\mathrm{D}} \approx 350 \mathrm{~V}$, ток $I_{\mathrm{D}} \approx 300 \mathrm{~mA}$, плотность ионного тока $J_{\mathrm{He}^{+}} \approx 0.4 \mathrm{~mA} / \mathrm{cm}^{2}$ (плотность потока ионов $\mathrm{He}^{+}$на поверхность образца $q=2.5 \cdot 10^{19} \mathrm{~m}^{-2} \cdot \mathrm{s}^{-1}$, давление $P_{\mathrm{He}}=2.6 \mathrm{~Pa}$. Температура зеркала $T$ во время облучения была в пределах $140-150^{\circ} \mathrm{C}$. Удаление дефектного приповерхностного слоя, сформированного в процессе полировки, производилось распылением с использованием $\mathrm{Ar}$ в качестве рабочего газа. Режим распыления ионами аргона: $P_{\mathrm{Ar}}=2.6 \mathrm{~Pa}, U_{\mathrm{D}} \approx 350 \mathrm{~V}, I_{\mathrm{D}} \approx 200 \mathrm{~mA}$, $J_{\mathrm{Ar}} \approx 0.7 \mathrm{~mA} / \mathrm{cm}^{2}$.

Толщина распыленного слоя измерялась методом взвешивания с использования аналитических весов CAS CAUW 220D с точностью измерения $\pm 0.01 \mathrm{mg}$. Для оценки толщины дефектного слоя использовались поликристаллические Мо-зеркала, полировка которых проводилась по той же технологии, что и полировка монокристаллических зеркал $[10,11]$. Эта же технология полировки будет использована при изготовлении входных зеркал для диагностических систем „Спектроскопия водородных линий“ и „Активная спектроскопия“ в ИТЭР. Морфология поверхности исследовалась на сканирующем электронном микроскопе Zeiss EVO MA 10. Толщина дефектного слоя определялась послойным распылением образца с шагом $\approx 20 \mathrm{~nm}$. Контроль удаления дефектного слоя проводился по факту проявления границ зерен. Толщина дефектного слоя на поликристаллическом зеркале составила $H \approx 200 \mathrm{~nm}$. Такая же толщина поверхностного слоя распылялась для удаления дефектного слоя с монокристаллических Мозеркал.

Измерение зеркального отражения и диффузного рассеяния проводилось на спектрофотометре Perkin Elmer Lambda 850.

\section{2. Результаты экспериментальных исследований}

Результаты исследования изменения спектральной зависимости коэффициента зеркального отражения при облучении ионами $\mathrm{He}^{+}$в условиях относительно высокого давления нейтрального газа $(\approx 2.6 \mathrm{~Pa})$ над облучаемой поверхностью для монокристаллических зеркал с кристаллографической ориентацией $\langle 110\rangle$ представлены на рис. 2.

Результаты измерений спектральной зависимости коэффициента диффузного рассеяния представлены на рис. 3.

Спектральные зависимости коэффициента зеркального отражения и диффузного рассеяния для монокристаллических зеркал с кристаллографической ориентацией $\langle 111\rangle$ до и после удаления дефектного слоя представлены на рис. 4 и 5. 

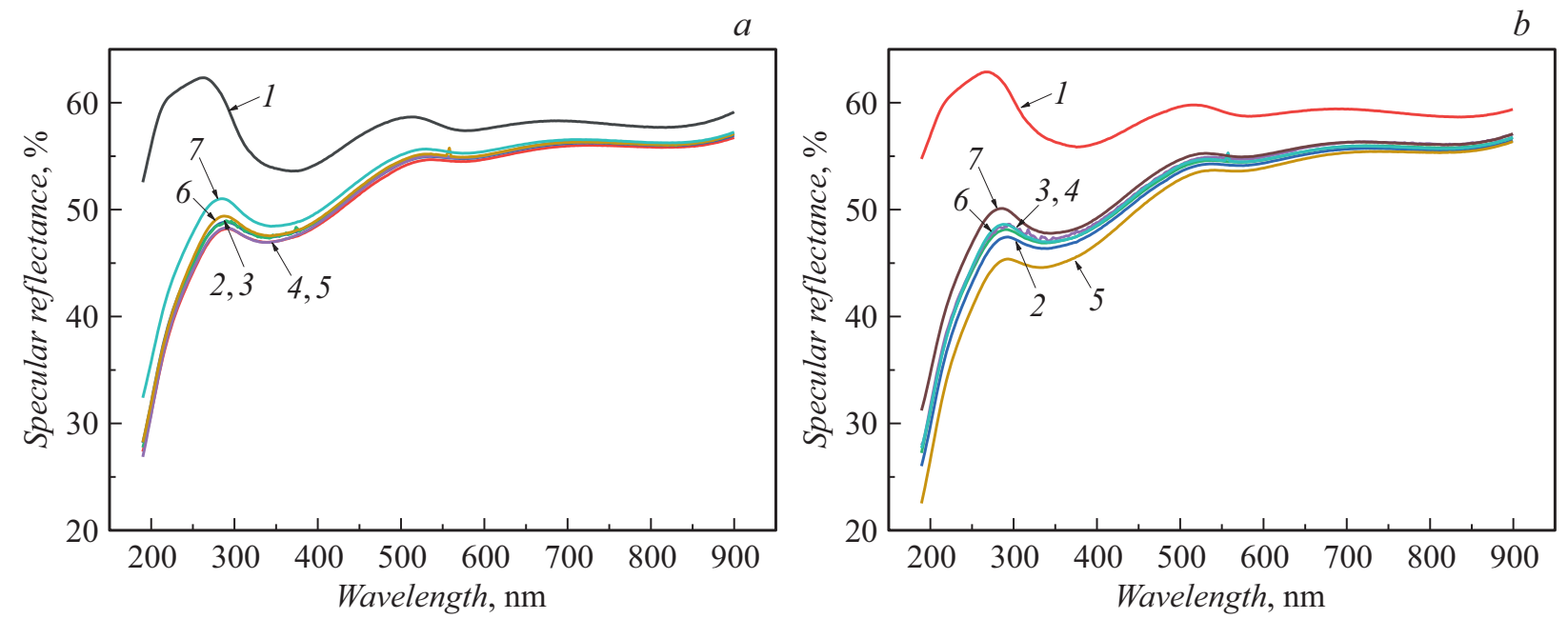

Рис. 2. Коэффициент зеркального отражения монокристаллического Мо-зеркала с кристаллографической ориентацией $\langle 110\rangle$ до $(a)$ и после $(b)$ удаления дефектного слоя: 1 - до облучения ионами $\mathrm{He}^{+}$; после облучения с флюенсом: $2-1.8 \cdot 10^{19}$, $3-3.6 \cdot 10^{19}, 4-5.4 \cdot 10^{19}, 5-7.2 \cdot 10^{19}, 6-1.12 \cdot 10^{20}, 7-1.62 \cdot 10^{20} \mathrm{ions} / \mathrm{cm}^{2}$.
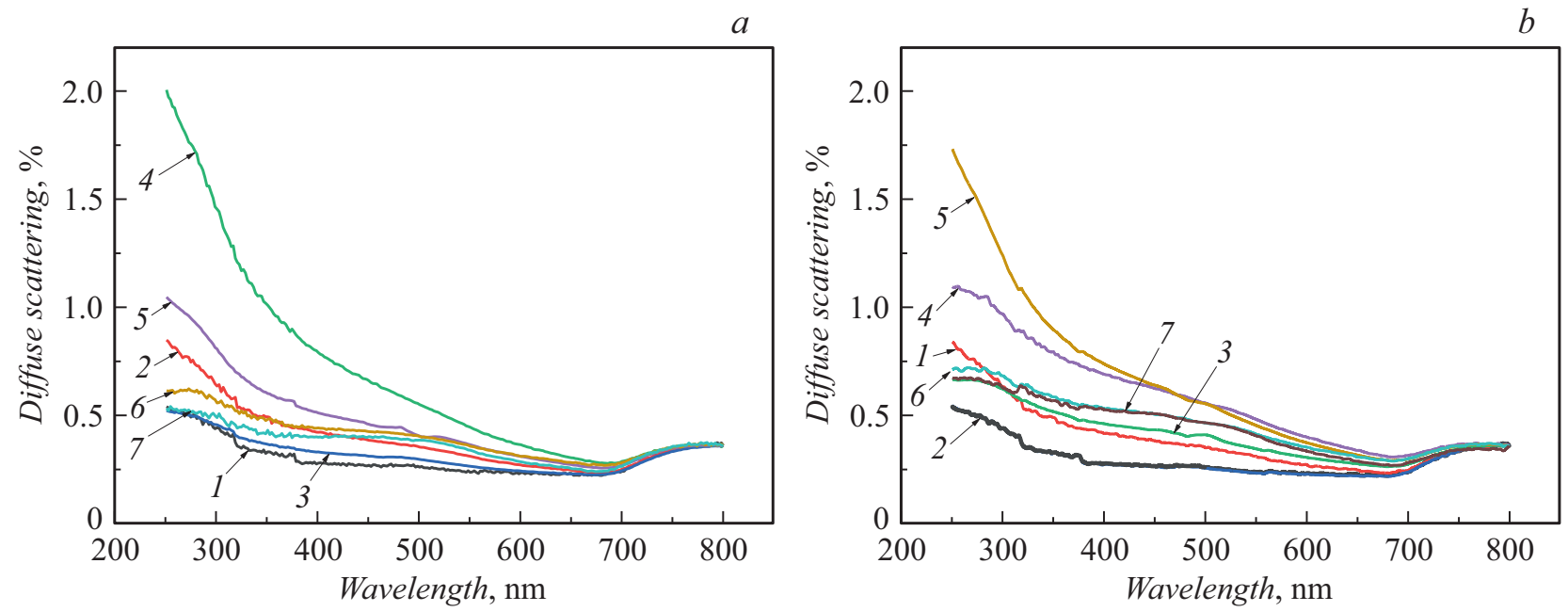

Рис. 3. Коэффициент диффузного рассеяния монокристаллического Мо-зеркала с кристаллографической ориентацией $\langle 110\rangle$ до $(a)$ и после $(b)$ удаления дефектного слоя: $1-$ до облучения ионами $\mathrm{He}^{+}$; после облучения с флюенсом: $2-1.8 \cdot 10^{19}, 3-3.6 \cdot 10^{19}$, $4-5.4 \cdot 10^{19}, 5-7.2 \cdot 10^{19}, 6-1.12 \cdot 10^{20}, 7-1.62 \cdot 10^{20} \mathrm{ions} / \mathrm{cm}^{2}$.

Вне зависимости от кристаллографической ориентации монокристалла относительно отражающей поверхности и наличия дефектного слоя, для всех исследованных образцов зеркал на начальном этапе облучения ионами гелия наблюдается резкое снижение коэффициента зеркального отражения. На длине волны $\lambda \approx 300 \mathrm{~nm}$ коэффициент зеркального отражения снижается более чем на $10 \%$. При дальнейшем облучении изменение коэффициента отражения не превышает нескольких процентов. При флюенсе выше $1 \cdot 10^{20} \mathrm{ions} / \mathrm{cm}^{2}$ наблюдается медленный рост коэффициента зеркального отражения. Также для всех исследованных образцов зеркал получена сходная динамика изменения диффузного рассеяния: первоначально происходит его рост и при флюенсе в диапазоне
$5.4 \cdot 10^{19}-7.2 \cdot 10^{19}$ ions $/ \mathrm{cm}^{2}$ наблюдается максимальное значение. При дальнейшем увеличении флюенса происходит уменьшение диффузного рассеяния практически до исходной величины.

Согласно [12], в разряде с полым катодом при больших значениях разрядного тока катодное падение потенциала (в темновом пространстве, где происходит ускорение распыляющих стенки ионов) практически совпадает с напряжением горения разряда. Расчет глубины внедрения ионов $\mathrm{He}^{+}$с энергией $350 \mathrm{eV}$ в программе TRIM дает значение $R \approx 4 \mathrm{~nm}$, а средний квадратичный разброс глубины проникновения составляет $\Delta R=2 \mathrm{~nm}$. Измеренная в ходе экспериментов скорость движения поверхности за счет распыления ионами Не составила $u \approx 0.5 \cdot 10^{-2} \mathrm{~nm} / \mathrm{s}$. Для максимального флюенса 


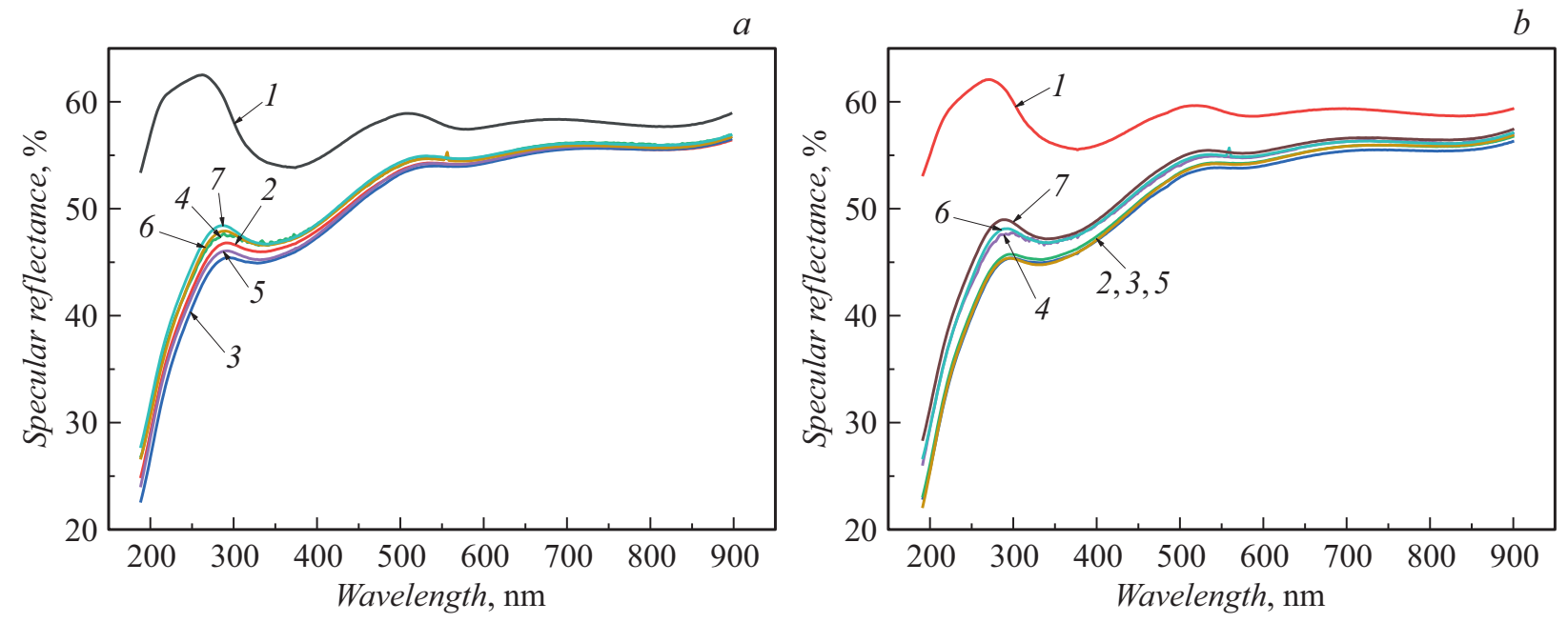

Рис. 4. Коэффициент зеркального отражения монокристаллического Мо-зеркала с кристаллографической ориентацией 〈111〉 до $(a)$ и после $(b)$ удаления дефектного слоя: 1 - до облучения ионами $\mathrm{He}^{+}$; после облучения с флюенсом: $2-1.8 \cdot 10^{19}$, $3-3.6 \cdot 10^{19}, 4-5.4 \cdot 10^{19}, 5-7.2 \cdot 10^{19}, 6-1.12 \cdot 10^{20}, 7-1.62 \cdot 10^{20} \mathrm{ions} / \mathrm{cm}^{2}$.
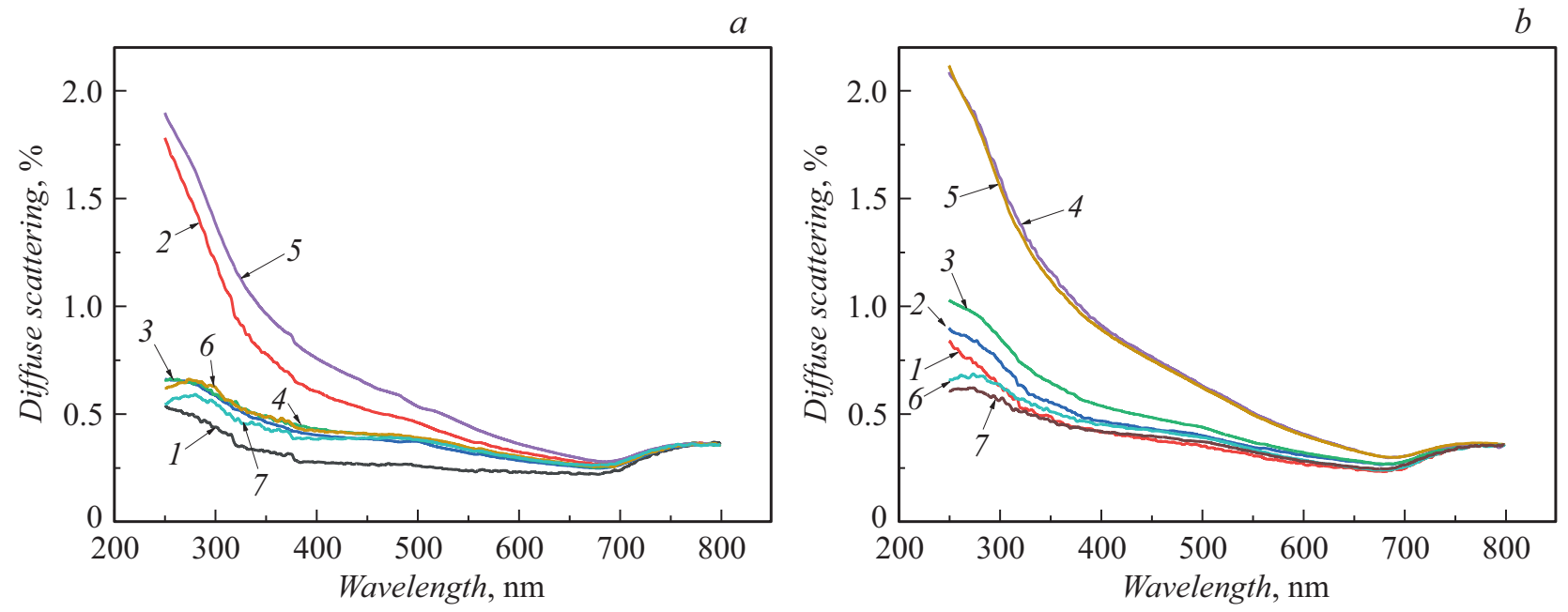

Рис. 5. Коэффициент диффузного рассеяния монокристаллического Мо-зеркала с кристаллографической ориентацией $\langle 111\rangle$ до $(a)$ и после $(b)$ удаления дефектного слоя: $1-$ до облучения ионами $\mathrm{He}^{+}$; после облучения с флюенсом: $2-1.8 \cdot 10^{19}, 3-3.6 \cdot 10^{19}$, $4-5.4 \cdot 10^{19}, 5-7.2 \cdot 10^{19}, 6-1.12 \cdot 10^{20}, 7-1.62 \cdot 10^{20} \mathrm{ions} / \mathrm{cm}^{2}$.

Не $\Phi=1.62 \cdot 10^{20}$ ions $/ \mathrm{cm}^{2}$ толщина распыленного слоя равна $\approx 130 \mathrm{~nm}$.

Сравнение полученных результатов показало, что для зеркал с кристаллографической ориентацией $\langle 110\rangle$ максимум роста диффузного рассеяния на начальном этапе облучения ионами $\mathrm{He}^{+}$примерно на 20\% меньше, чем для зеркал с ориентацией $\langle 111\rangle$, т.е. они обладают несколько большей устойчивостью к облучению.

Исследование морфологии поверхности зеркала на сканирующем электронном микроскопе до и после облучения не выявило каких-либо заметных изменений, поскольку его увеличение было недостаточным для регистрации столь малых $(\approx 1 \mathrm{~nm})$ дефектов поверхности. Предварительное удаление дефектного приповерхностного слоя, сформированного при полировке зеркала, практически не повлияло на динамику изменения оптических свойств при ионном облучении в рассматриваемых условиях, а дополнительное распыление поверхностного слоя толщиной $\approx 100 \mathrm{~nm}$ ионами $\mathrm{Ar}^{+}$ после облучения образцов ионами $\mathrm{He}^{+}$практически полностью восстанавливает первоначальное значение спектрального коэффициента отражения и диффузного рассеяния зеркал.

\section{3. Анализ полученных результатов}

Полученные результаты показывают уменьшение коэффициента зеркального отражения $R$ и увеличение диффузного рассеяния молибденового зеркала после облучения ионами Не. В то же время зеркало с дефектным 
слоем, образованным при полировке, существенного уменьшения $R$ по сравнению зеркалом после удаления этого слоя распылением ионами Ar не дает. Облучение ионами $\mathrm{Ar}$ тоже не приводит к снижению коэффициента отражения. Поскольку облучение ионами $\mathrm{Ar}$ вносит большие изменения в шероховатость поверхности, а изменения оптических характеристик происходит только после облечения ионами Не и не зависят от наличия дефектного слоя, то это означает, что наблюдавшиеся изменения не обусловлены шероховатостью поверхности и дефектностью слоя.

Отличительной особенностью облучения ионами Не является образование гелиевых пузырьков, которые, сливаясь при достижении критической дозы, образуют блистеры. Образование пузырьков есть следствие плохой растворимости гелия в металлах и появление новой фазы (пузырьков) при превышении концентрации гелия над равновесной концентрацией $C_{\text {eq }} \approx N \exp (-H / T)$, где $H$ - энергия растворения, обычно составляющая несколько $\mathrm{eV}, N$ - число атомов в единице объема молибдена [13]. Малый коэффициент распыления гелием способствует его большему накоплению в приповерхностных слоях по сравнению с аргоном и другими тяжелыми атомами. Представление об образовании гелиевых блистеров при слиянии мелких пузырьков утвердилось еще в ранних работах по блистерингу [14]. В работах по образованию структуры типа „металлического пуха“ при облучении ионами гелия пузырьки гелия являются основой теоретической модели развития такой структуры [15]. Пузырьки гелия в поверхностном слое Мо наблюдались в работе [16]. Ямки от вскрывшихся пузырьков гелия на молибдене наблюдались в работе [17]. В наших экспериментах доза облучения меньше критической дозы образования блистеров. Однако после последующего облучения ионами Ar на молибдене, облученном ионами Не при аналогичных условиях, наблюдались блистеры, размером $\sim 1 \mu \mathrm{m}$ [18]. Облучение $\mathrm{Ar}$ без предварительного облучения Не не показало наличие блистеров.

Поэтому естественно предположить, что в представленных здесь экспериментах гелиевые пузырьки образуются у поверхности и ответственны за уменьшение коэффициента отражения. Причиной влияния гелиевых пузырьков на уменьшение зеркального отражения света может быть рэлеевское рассеяние света на пузырьках. Наноразмерные гелиевые пузырьки с большим давлением являются инородным включением в молибден и имеют отличный коэффициент преломления. На гелиевых пузырьках в приповерхностном слое происходит рэлеевское рассеяние света. Пузырек в поле световой волны поляризуется, его диполь осциллирует так же, как диполь частицы в газе или в вакууме в поле световой волны, при этом его излучение когерентно падающему свету и имеет максимум перпендикулярно падающему лучу. В этом участвуют не крупные пузыри, которые образуют блистеры, а мелкие пузырьки с размером меньше длины волны, поскольку рэлеевское рассеяние характерно только для объектов меньше длины волны. Интенсивность света, рассеянного от частицы (гелиевого пузырька) размером $r_{0}$, по механизму рэлеевского рассеяния, пропорциональна $r_{0}^{6}$ и обратно пропорциональна $\lambda^{4}$ ( $\lambda$ - длина волны излучения) [19]

$$
I \sim r_{0}^{6} / \lambda^{4} I_{0}
$$

где $I_{0}$ - интенсивность падающего потока света. Интенсивность отраженного света при наличии пузырьков уменьшается на величину интенсивности рэлеевского рассеяния от всех пузырьков в объеме $V$, формирующем отраженную волну. Глубина этой области равна толщине скин-слоя [19]:

$$
d=\left(\varepsilon_{0} c \rho \lambda / \pi\right)^{1 / 2},
$$

где $\varepsilon_{0}$ - диэлектрическая постоянная, $c-$ скорость света, $\rho$ - удельное сопротивление металла (для Мо $\left.\rho \approx 8 \cdot 10^{-8} \Omega \cdot \mathrm{m}\right)$. Для исследованных длин волн толщина скин-слоя $d$ находится в пределах $4.5-8 \mathrm{~nm}$. Мелкие гелиевые пузырьки имеют примерно такой же размер. Площадь области, формирующей отраженную волну одного фотона, равна $\lambda^{2}$, так что объем области, формирующей рассеянную волну, $V \sim \lambda^{2.5}$. Число пузырьков в области, формирующей отраженную волну, равно $N_{b}=C_{b} V \sim \lambda^{2.5}$, где $C_{b}-$ концентрация пузырьков в приповерхностной области. Концентрация пузырьков у поверхности мало меняется с дозой. Зависимости $R(\lambda)$ для разных доз облучения ионами Не близки. Поскольку $V=d \lambda^{2} \sim \lambda^{2.5}$, а $I \sim \lambda^{-4}$, то интенсивность отраженной волны уменьшается на величину $N_{b} I=C_{b} V I \sim \lambda^{-3 / 2}$.

Тогда отношение коэффициента отражения поверхности с пузырьками Не к коэффициенту отражения поверхности, не облученной ионами $\mathrm{He}^{+}$, равно

$$
R_{\mathrm{He}} / R=1-k / \lambda^{3 / 2},
$$

где $k$ - подгоночный коэффициент.

На рис. 6 приведены зависимости $R_{\mathrm{He}} / R(\lambda)$ для поверхностей $\langle 110\rangle$ и $\langle 111\rangle$, а также кривая функции $R_{\mathrm{He}} / R=1-k / \lambda^{3 / 2}$ при $k=1000$.

Оценим теперь размеры гелиевых пузырьков в приповерхностном слое толщиной $d$. При энергии ионов $\mathrm{He}^{+}$, равной $350 \mathrm{eV}$, максимальная энергия, передаваемая атому Мо, составляет $29 \mathrm{eV}$, а энергия смещения атома Мо равна $33 \mathrm{eV}$ [20], поэтому образования гелиевых пузырьков в результате объединения атомов гелия и вакансий, как это происходит [21] при больших энергиях ионов $\mathrm{He}^{+}$, в нашем случае не происходит. Пузырек образуется в результате объединения атомов гелия и выталкивания с поверхности пузырька петли дислокации, этот механизм был предложен еще в одной из ранних работ по блистерингу [14]. Для образования петли дислокации с радиусом $r_{0}$, который примерно равен радиусу пузырька, необходимо давление

$$
P \approx G b / r_{0},
$$

где $G$ - модуль сдвига, $b$ - вектор Бюргерса дислокации. Такое давление в пузырьке есть условие образования пузырька, и оно обязательно для пузырька 


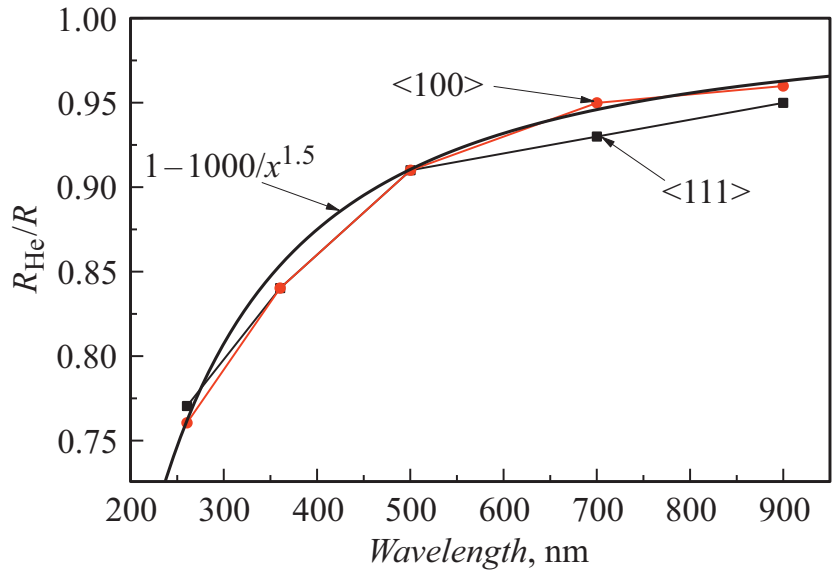

Рис. 6. Зависимость отношения коэффициентов зеркального отражения $R_{\mathrm{He}}$ молибденового зеркала, облученного ионами $\mathrm{He}^{+}$, и зеркала после удаления дефектного слоя с пузырьками гелия $R$ от длины волны.

не радиационного происхождения. Это очень большие давления, в наноразмерных пузырьках оно составляет несколько десятков гигапаскалей. Напряжение сжатия вокруг пузырька, намного превосходящее поверхностную энергию пузырька, сдерживает давление внутри пузырька. Ввиду большой плотности гелия в пузырьке его коэффициент преломления отличен от единицы.

В этом случае образование пузырьков происходит без участия вакансий и возможно по всей глубине слоя, в который проник гелий в результате диффузии $(D t)^{1 / 2}$. Согласно [22], энергия активации диффузии атомов гелия в молибдене равна $E_{a}=0.63 \mathrm{eV}$, a предэкспоненциальный фактор $D_{0}=6.5 \cdot 10^{-4} \mathrm{~m}^{2} / \mathrm{s}$. При температуре облучения $T=420 \mathrm{~K}$ получаем $D=D_{0} \exp \left(-E_{a} / T\right)=1.7 \cdot 10^{-11} \mathrm{~m}^{2} / \mathrm{s}$, и при $t>R^{2} / D \approx$ $\approx 10^{-6}$ s концентрация атомов гелия устанавливается у поверхности в результате баланса поступления атомов Не при облучении и диффузии к поверхности на уровне

$$
\begin{gathered}
q=D C / R, \\
C_{0}=q R / D \approx 6 \cdot 10^{21} \mathrm{~m}^{-3} .
\end{gathered}
$$

Концентрация атомов Не в молибдене значительно превышает равновесную концентрацию, поэтому критический размер пузырька, при котором объединение атомов гелия преобладает над отрывом атомов, равен $m \sim 1$ [13]. То есть можно считать, что объединяются свободно диффундирующие атомы Не. Концентрация пузырьков $C_{b}$ описывается уравнением

$$
\begin{gathered}
\mathrm{d} C_{b} / \mathrm{d} t=4 \pi a D C^{2}, \\
C_{b}=4 \pi a D C^{2} t,
\end{gathered}
$$

где $a-$ радиус атома Не, $t-$ время облучения.

Через время $t_{1}=(4 \pi a D C)^{-1} \approx 0.04 \mathrm{~s}$ концентрация пузырьков $C_{b}$ становится больше концентрации атомов Не $C$. При $t>t_{1}$ образование новых пузырей становится мало, атомы Не присоединяются к уже имеющимся пузырькам. Полагаем при $t>t_{1} C_{b}=C_{0}$.

Пузырьки растут, число атомов Не в пузырьке определяется уравнением

$$
\mathrm{d} m / \mathrm{d} t=4 \pi D \operatorname{Cam}^{1 / 3} .
$$

Пока концентрация атомов Не определяется диффузией к поверхности и равна $C_{0}, m \approx 130 t^{3 / 2}$. По мере роста пузырьков и глубины слоя $(D t)^{1 / 2}$, в котором они образовались, наряду со стоком к поверхности поступающие атомы Не присоединяются к пузырькам, и их концентрация убывает в соответствии с уравнением

$$
\begin{gathered}
q=D C\left(1 / R+4 \pi a m^{1 / 3} C_{b}(D t)^{1 / 2}\right), \\
C=C_{0} /\left(1+4 \pi a R m^{1 / 3} C_{b}(D t)^{1 / 2}\right) .
\end{gathered}
$$

Второй член в знаменателе (7) становится больше единицы за время $t \approx 15 \mathrm{~s}$, значительно меньшее, чем время облучения зеркал гелием, поэтому можно считать, что число атомов Не в пузырьке растет в соответствии с уравнением

$$
\begin{gathered}
\mathrm{d} m / \mathrm{d} t=q / C_{b}(D t)^{1 / 2}, \\
m=2 q t^{1 / 2} / C_{b}(D)^{1 / 2} .
\end{gathered}
$$

Последнее выражение отражает тот факт, что все поступающие атомы Не попадают в пузырьки, находящиеся в слое $(D t)^{1 / 2}$. Поскольку время образования пузырьков значительно меньше, чем время их роста, то относительный разброс размеров пузырьков мал, все пузырьки примерно одного размера. Радиус пузырька при этом равен

$$
r_{0}=a m^{1 / 3} \approx a\left(2 q / C_{b}\right)^{1 / 3} D^{-1 / 6} t^{1 / 6} \approx 0.4 t^{1 / 6} \mathrm{~nm} .
$$

Как видно из (9), при минимальной дозе в эксперименте, при $t=7200 \mathrm{~s}$, радиус пузырька составляет $r_{0}=a m^{1 / 3} \approx 1.7 \mathrm{~nm}$. При увеличении дозы облучения $r_{0}$ растет, и в соответствии с (1) увеличивается интенсивность рэлеевского рассеяния. Однако когда размер пузырьков $2 a$ становится больше толщины скин-слоя, $2 a m^{1 / 3} \gtrsim d$, пузырьки уже не попадают целиком в поле световой волны, и рэлеевское рассеяние на них уменьшается. При максимальной дозе облучения $r_{0} \approx 2.5 \mathrm{~nm}$. Уменьшение интенсивности рэлеевского рассеяния наиболее выражено для малых длин волн, для которых толщина скин-слоя $\left(d \sim t^{1 / 2}\right)$ меньше. Подчеркнем, что для рэлеевского рассеяния на гелиевых пузырьках в данном случае необходимо, чтобы размер пузырьков был меньше не только длины волны, но и толщины скинслоя.

Таким образом, динамика образования и роста пузырьков Не позволяет понять изменение отражения света от поверхности зеркала при увеличении дозы облучения.

В работе [23] наблюдалось такое же, преимущественно для коротких длин волн $\lambda$, снижение коэффициента отражения зеркала из родия после облучения ионами дейтерия. Полагаем, что это тоже является следствием 
образования пузырьков дейтерия и рэлеевского рассеяния света на них. Следовательно, обнаруженный эффект возможен и при очистке в дейтериевой плазме зеркал из металла с плохой растворимостью изотопов водорода, в которых возможно образование пузырьков с высоким давлением.

\section{Заключение}

Обнаружен эффект изменения спектральной зависимости коэффициента зеркального отражения и диффузного рассеяния после облучения низкоэнергетическими ионами $\mathrm{He}^{+}$отражающей поверхности механически полированных монокристаллических Мо-зеркал. Наблюдаемые изменения объяснены формированием в приповерхностном скин-слое наноразмерных пузырьков с большим внутренним давлением Не и рэлеевским рассеянием на них падающего излучения. В результате рэлеевского рассеяния уменьшается коэффициент зеркального отражения и увеличивается диффузное рассеяние. Предложена модель формирования нанопузырьков в приповерхностном отражающем слое, объясняющая изменения спектрального коэффициента отражения при увеличении дозы облучения. Рассматриваемый эффект следует учитывать при проектировании плазменных систем очистки входных зеркал в оптических диагностических системах ИТЭР, при анализе данных, полученных после использования Не в качестве рабочего газа для удаления загрязнений.

\section{Конфликт интересов}

Авторы заявляют, что у них нет конфликта интересов.

\section{Список литературы}

[1] Design Requirements and Guidelines Level 2 (DRG2). ITER Document. G A0 GDRD 3 01-07-19 R1.0. 477 (2001).

[2] V. Kotov, D. Reiter, A.S. Kukushkin, A. Krimmer, A. Kirschner, S. Wiesen, P. Borner. Final report on the ITER service contract C4T/09/71/OLT CHD/DIAGNOSTIC (2011).

[3] D. Ivanova, M. Rubel, A. Widdowson, P. Petrsson, J. Likonen, L. Marot, E. Alves, A. Garcia-Carrasco, G. Pintsuk. Physica Scripta, 159, (2014).

[4] А.В. Рогов, Ю.В. Капустин. УПФ, 4 (3), 240 (2016).

[5] L. Moser, L. Marot, R. Steiner, R. Reichle, F. Leipold, C. Vorpahl, F. Le Guern, U. Walach, S. Alberti, I. Furno, R. Yan, J. Peng, M. Ben Yaala, E. Meyer. Physica Scripta, 170, 014047 (2017). DOI: 10.1088/1402-4896/aa8f30.

[6] N. Antonov. PDR DA System Design Description 55.E2 HAlpha and Visible Spec. DA Design Description Document. 209 (2017). IDM UID: TWRHG4.

[7] M.G. Von Hellermann, R. Barnsley, W. Biel, E. Delabie, N. Hawkes, R. Jaspers, D. Johnson, F. Klinkhamer, O. Lischtschenko, O. Marchuk, B. Schunke, M.J. Singh, B. Snijders, H.P. Summers, D. Thomas, S. Tugarinov, P. Vasu. Nucl. Inst. and Meth. in Phys. Res. A., 623 (2), 720 (2010).
[8] Y. Yamamura, H. Tawara. Energy Dependence of IonInduced Sputtering Yields from Monoatomic Solids at Normal Incidence. Research report. NIFS-DATA-23. 110 (1995).

[9] А.В. Рогов, Ю.В. Капустин. ПТЭ, 2, 150 (2018). DOI: $10.7868 / \mathrm{S} 0032816218020064$

[10] А.В. Рогов, Ю.В. Мартыненко, Ю.В. Капустин, С.С. Фанченко, Н.Е. Белова. ЖТФ, 88 (5), 722 (2018). DOI: $10.21883 /$ JTF.2018.05.45901.2243

[11] А.В. Рогов, Ю.В. Капустин, Ю.В. Мартыненко. Поверхность. Рентгеновские, синхротронные и нейтронные исследования, 8, 87 (2017). DOI: $10.7868 / \mathrm{S} 0207352817080121$

[12] А.С. Метель. ЖТФ, 55 (10), 1928 (1985).

[13] Я.И. Френкель. Кинетическая теория жидкостей (Наука, Л., 1975)

[14] J.H. Evans. J. Nucl. Mat., 44, 25 (1973).

[15] S.I. Krasheninnikov. Physica Scripta, 145, 014040 (2011). DOI: 10.1088/0031-8949/2011/T145/014040

[16] A. Garcia-Carrasco, P. Petersson, A. Hallén, J. Grzonka, M.R. Gilbert, E. Fortuna-Zalesna, M. Rubel. Nucl. Instr. Meth. Physics Res. B, 382, 91 (2016). DOI: $10.1016 /$ j.nimb.2016.02.065

[17] G. De Temmerman, K. Bystrov, J.J. Zielinski, M. Balden, G. Matern, C. Arnas, L. Marot. J. Vac. Sci. Tech. A, 30, 041306 (2012). DOI: $10.1116 / 1.4731196$

[18] А.В. Рогов, Ю.В. Капустин, В.М. Гуреев, А.Г. Домантовский. Поверхность. Рентгеновские, синхротронные и нейтронные исследования, в печати, (2021). DOI: $10.31857 / \mathrm{S} 1028096021060121$

[19] Физический энциклопедический словарь, под ред. Б.А. Введенского. (Советская энциклопедия, М., 1965)

[20] В. Экштайн. Компьютерное моделирование взаимодействия частии, с поверхностью твердого тела (Мир, М., 1995)

[21] М.И. Гусева, Ю.В. Мартыненко. УФН, 135 (4), 671 (1981).

[22] W. Weiguo, Y. Junfeng, W. Xianping, X. Chunyi, L. Renhong, C. Junling, F. Qianfeng. Plasma Sci. Technol., 11 (3), 261 (2009). DOI: 10.1088/1009-0630/11/3/02

[23] M. Ben Yaala, L. Moser, R. Steiner, B. Butoi, P. Dinca, P. Petersson, L. Marot, E. Meyer. Nuclear Fusion, 59(9), 096027 (2019). DOI: 10.1088/1741-4326/ab2d31 